\title{
Crítica social nas entrevistas de Sophia de Mello Breyner Andresen
}

\author{
Social criticism in the interviews \\ of Sophia de Mello Breyner Andresen
}

Rita Barbosa de Oliveira

Universidade Federal do Amazonas (UFAM), Manaus, Amazonas / Brasil ritapsocorro@gmail.com

Resumo: Na maioria das ocasiões em que Sophia de Mello Breyner Andresen concede entrevista há a descontração de quem conversa com um amigo, e muitos dos interlocutores realmente o são, como Eduardo Prado Coelho, Maria Armanda Passos, Miguel Serras Pereira e José Carlos de Vasconcelos. Revelando variedade de assunto, os textos "Sophia de Mello Breyner Andresen fala a Eduardo Prado Coelho", "Sophia de Mello Breyner Andresen: 'Escrevemos poesia para não nos afogarmos no cais...", "Sou uma mistura de Norte e Sul" e "Sophia: a luz dos versos", transcritos no Catálogo da Exposição "Sophia de Mello Breyner Andresen - uma vida de poeta" (MORÃO; AMADO, 2010), organizado por Paula Morão e Teresa Amado, publicado pela Biblioteca Nacional de Portugal, motivam a discussão a respeito de algumas inquietações da citada poetisa, apresentadas ora com determinado humor mordaz, ora com gravidade, em que questões sobre língua, religião, cidade, ecologia, participação política, morte, o mal, o fazer poético são trazidas para o diálogo.

Palavras-chave: Sophia de Mello Breyner Andresen; entrevista; crítica social. 
Abstract: On most occasions when Sophia de Mello Breyner Andresen gives an interview, there is the relaxation of those who talk with a friend, and many of the interlocutors really are such as Eduardo Prado Coelho, Maria Armanda Passos, Miguel Serras Pereira and José Carlos de Vasconcelos. Revealing a variety of subject matter, the texts "Sophia de Mello Breyner Andresen speaks to Eduardo Prado Coelho", "Sophia de Mello Breyner Andresen: "We wrote poetry not to drown in the quay ...", "I am a mixture of North and South "And" Sophia: the light of the verses ", transcribed in the Catalog of the Exhibition" Sophia de Mello Breyner Andresen - a life of poet "(2010), organized by Paula Morão and Teresa Amado, published by the National Library of Portugal, with respect to some of the poet's concerns, presented with a certain biting humor, sometimes with seriousness, where questions about language, religion, city, ecology, political participation, death, evil, poetic making are brought into dialogue.

Keywords: Sophia de Mello Breyner Andresen; interview; social criticism.

Data de submissão: 13 de setembro de 2018

Data de aprovação: 21 de janeiro de 2019

\section{Introdução}

A entrevista, de natureza informativa e predominantemente oral, constitui-se de uma modalidade de texto jornalístico baseada no diálogo entre os partícipes de tal modo que, em situação ideal, eles "interagem, se modificam, se revelam, crescem no conhecimento do mundo e deles próprios" (MEDINA, 2004, p. 8). Implica uma maneira de estar à vontade dos interlocutores, uma arte de perguntar, ouvir e conversar, em que o diálogo se concentra no entrevistado, motivando-o e permitindo, assim, vir à tona sua subjetividade, entrelaçada à objetividade necessária em decorrência da diversidade do público a quem a entrevista é divulgada, jornais impressos e digitais.

Apesar de sua duração ser efêmera, a entrevista com artistas perde esse caráter ao ser retirada das páginas dos jornais e revistas impressos 
(e, mais recentemente, outros meios eletrônicos) para serem reunidas em publicações em livro ou em meios eletrônicos, facilitando o acesso do material a pesquisadores. A esse respeito, Massaud Moisés esclarece que,

graças à linguagem e liberdade que a envolve, [os textos de jornal] podem aspirar, ainda que secretamente, a permanecer para além do jornal. Mesmo nessa hipótese, levarão sempre a chancela da anfibologia originária, pois quando se reúnem em livro, nem por isso se despojam da feição jornalística (MOISÉS, 1997, p. 157).

De acordo com a ambivalência de literatura e reportagem, a entrevista consiste num documento no qual se verifica o entendimento de acontecimentos individuais e coletivos, no qual predomina um eu que, ao mesmo tempo que fala com o outro, se contempla, se desvenda, quando expressa verdades para ele indiscutíveis e tão secretas que talvez só possam ser reveladas na presença de um interlocutor, o qual, para alcançar essa aproximação, demonstra possuir experiências afins do entrevistado. Por isso, o autodesvendamento torna a entrevista análoga ao diário e à autobiografia, e este é o motivo de Sophia de Mello Breyner Andresen afirmar que não gosta de dar entrevistas - elas são confessionais (ANDRESEN apud PASSOS, 1982, p. 5; ANDRESEN apud VASCONCELOS, 1991, p. 11), não obstante as considerações que indicam a importância da entrevista como documento para a história da cultura.

As entrevistas destacadas para a discussão neste artigo são: "Sophia de Mello Breyner Andresen fala a Eduardo Prado Coelho", "Sophia de Mello Breyner Andresen: 'Escrevemos poesia para não nos afogarmos no cais...", "Sou uma mistura de Norte e Sul" e "Sophia: a luz dos versos", que foram republicadas no Catálogo da Exposição "Sophia de Mello Breyner Andresen - uma vida de poeta" (2010) e integram o conjunto de documentos e demais objetos do arquivo da poetisa junto à Biblioteca Nacional de Portugal, instituição encarregada de sua preservação, classificação e catalogação, sob a coordenação de Maria Andresen de Sousa Tavares, conforme se lê nos sites "Sophia" (BIBLIOTECA NACIONAL DE PORTUGAL, [s.d.]), da mencionada biblioteca, e "O espólio de Sophia na BNP" (TAVARES, [s.d.]). Tais entrevistas, acompanhadas de outras, foram digitalizadas e estão disponíveis no último site citado, fato que viabiliza a pesquisa e ressalta a consistência histórica e literária do acervo. Esses documentos preservam algumas ideias da poetisa sobre cultura e poesia. 
Vale ressaltar que, nas entrevistas acima elencadas, Sophia nem sempre revela todo seu pensamento sobre uma questão, antes suspende sua resposta no meio de sua fala, levando o entrevistador a completar a ideia ou mudar de assunto e, às vezes, se ele volta àquela pergunta, a reposta dela torna-se mais desviante. Ao mesmo tempo, verifica-se, nelas, a fluidez da conversa a indicar a ligação intelectual e afetiva com $o$ entrevistador.

Embora não haja ainda estudos acadêmicos exclusivamente sobre as entrevistas de Sophia e apesar de, a partir da década de 60, terem sido publicadas dissertações, teses, livros, artigos em revistas, jornais e realizados congressos sobre variados temas de sua obra, fator que mostra a consagração da autora em seus país e no exterior, algumas dessas intervenções foram citadas nos artigos das Actas do Colóquio Internacional Sophia de Mello Breyner Andresen, publicadas em 2013 (TAVARES; CENTRO NACIONAL DE CULTURA), bem como nos prefácios aos livros da poeta editados pela Assírio \& Alvim, entre 2013 e 2016. Neste sentido, as entrevistas permanecem a oferecer relevante material para investigação.

\section{Diálogo tenso}

As citadas entrevistas foram primeiramente publicadas nas décadas de 80 e 90, quando Portugal reorganizava a vida política após a ditatura de Salazar e nelas se verifica a liberdade de expressão por meio da crítica da poetisa a comportamentos do homem português que vivia nos centros urbanos e às intervenções violentas na paisagem das regiões litorâneas do país. Não poderia deixar de ser objeto de debate o novo momento por que passava Portugal, época não mais apenas cercada de expectativas de transformações socioeconômicas, mas também alvo de frustração quanto ao encaminhamento que as ações individuais e as necessidades coletivas estavam tomando. Nesse contexto, a poetisa observava que "a base da democracia [...] não são as eleições, estas são apenas um meio, e até com bastantes defeitos; a base da democracia são os direitos individuais. E em Portugal é difícil as pessoas fazerem respeitar os seus direitos" (ANDRESEN apud VASCONCELOS, 1991, p. 8). A necessidade de as pessoas tomarem consciência da vida partilhada, para a qual é exigido o cuidado de si e do outro, fundamenta o espírito crítico da autora. 
A crítica à degradação da qualidade de vida na cidade concentra-se em Lisboa, possivelmente porque era onde Sophia residia e presenciava diariamente os problemas de infraestrutura, junto com a substituição de prédios históricos por outros que rompiam com o padrão arquitetônico da cidade. Ela se refere a essas questões com mordacidade na conversa com Miguel Serras Pereira (1985) e trata de modo semelhante a administração pública que desfigurou a arquitetura, as estradas das praias da Granja, de D. Ana e de Lagos, fato que prejudicou o ritmo da vida dos moradores daquelas regiões, conforme se lê na entrevista a José Carlos de Vasconcelos (1991).

Sophia reconhece que houve uma cidade, hipodâmica, na Grécia Antiga, que poderia ser referência para a reconstrução das cidades do país, mas que exigiria a tomada de consciência de seus habitantes sobre a importância de participarem das decisões e organização para seu funcionamento. Certamente a ideia seria atualizada para as necessidades das pessoas em cada lugar: centro urbano, litoral, área de montanhas.

Outro aspecto para o qual a autora direciona a crítica mordaz consiste na dicção da língua portuguesa, de cujas palavras, segundo ela, são suprimidas as vogais, fato que ela atribui à descontração na fala estimulada principalmente pelos profissionais do rádio e televisão (PEREIRA, 1985; PRADO COELHO, 1986). A poetisa não é uma defensora do purismo da língua materna, porque ela foi contrária ao Acordo Ortográfico (VASCONCELOS, 1991, p. 11) por entender que as variantes linguísticas decorrem das diferenças culturais dos povos falantes do português e não rompem com sua estrutura, antes a enriquecem, com as palavras novas e com as permanências de outras que são pouco utilizadas na vida diária em algumas regiões ou países. A crítica de Sophia direciona-se para a fala da língua portuguesa a advertir que a pronúncia pode levar à ruptura da estrutura das palavras, argumento pertinente tendo em vista que a língua portuguesa possui os marcadores de gênero, número, tempo e circunstância no final das palavras. Por outro lado, a poetisa desconsidera ser na expressão oral que acontecem as variantes linguísticas. A polêmica fica de certo modo reiterada quando a poetisa destaca a fala de uma mulher do Brasil, no "Poema de Helena Lanari", para elogiar o modo excelente de falar a língua portuguesa, indicado pela pronúncia melodiosa dos fonemas: "Gosto de ouvir o português do Brasil/ Onde as palavras recuperam a sua substância total/ (...) Quando 
Helena Lanari dizia o 'coqueiro'/ O coqueiro ficava muito mais vegetal" (ANDRESEN, 2014, p. 99).

A respeito da falta de conhecimento da história do país por parte dos portugueses, sabe-se que, nos regimes de exceção política, as pessoas são proibidas de pensar sobre a realidade em que vivem, são torturadas, assassinadas ou expulsas para o exílio, caso transgridam as imposições. Isso impede que a história do país seja discutida pelas pessoas maduras e conhecida pelos jovens e crianças. Sophia prefere, em vez de ponderar sobre esse fator, ironizar o desconhecimento da história de Portugal, tendo em vista que repensar essa história de enfrentamento dos mares, de lutas para libertar-se da submissão à União Ibérica e até pelo fim da ditadura fortaleceria o espírito dos portugueses. Ao contrário de sua expectativa, já se passaram alguns anos após o 25 de abril, e ela não viu indícios de transformações decisivas naquele sentido.

O descuido com a cidade, com o modo de falar a língua e o desconhecimento da história do país por parte dos portugueses, na opinião de Sophia, constituíam o conjunto de motivos por ela relacionados para fazer a crítica social e política e corresponderiam aos pontos principais para a reconstrução de Portugal após mais de trinta anos de cerceamento das liberdades, restrições à economia, a medidas educacionais, trabalhistas e de isolamento perante os demais países europeus. Seria, no entanto, pouco provável que os portugueses, vitimados por aquele longo tempo, assumissem prontamente os direitos e deveres de cidadãos tendo em vista que essas premissas haviam sido suprimidas. Sophia destacava a cultura portuguesa em oposição àqueles três fatores que impediam o país de redimensionar a vida sociopolítica, os prédios construídos no período das Navegações, os poetas que consagraram e reavivaram a história de Portugal e também outros pensadores cujas ideias contribuíam para a reflexão sobre as exigências para reconstruir socialmente o país.

As três questões acima elencadas, em nosso entendimento, são problematizadas por Sophia por se constituírem como perigos para o retrocesso político e o retorno de medidas ditatoriais com seus desgovernos. Por isso, há a advertência de que os problemas relativos ao descuido com a cidade, a língua e a história precisavam ser corrigidos, a partir do reconhecimento dos portugueses de que tal cenário representava o Mal. Nesse contexto, a situação era agravada pelo fato de pessoas que se beneficiaram, de algum modo, da ditadura, ou que tiveram suas liberdades civis tão cerceadas que ainda não teriam a capacidade de entender os 
males provocados pela ditadura, ou ainda aquelas que, por não terem sofrido os traumas da ditadura, mesmo que os meios de comunicação denunciassem os crimes cometidos, eram indiferentes aos efeitos de um regime de exceção.

Essa ideia de Sophia remete ao descompasso predominante na sociedade, no mundo ocidentalizado, relacionado ao Mal, ao qual ela se refere metaforicamente no diálogo com Prado Coelho: "sabe que em Delfos o Python ficou a apodrecer - o Apolo não o enterrou... O Mal não está enterrado" (1986, p. 15). Ela reitera a ideia para Maria Armanda Passos: "o mal é uma negatividade total, um puro princípio de destruição - do mal não nasce nada" (1982, p. 4).

A advertência de Sophia para se ficar atento ao Mal remete ao pensamento de Jean Baudrillard de que o Mal está em toda parte metamorfoseado nas diversas formas virais. $\mathrm{O}$ fato de dele não falarmos nos torna vulneráveis a sua saída dos espaços onde ele se camufla e a seu fortalecimento. Para o filósofo, a recusa a falar a respeito do Mal e a legalização das formas em que este se manifesta nos tornam seus cúmplices quando não nos opomos a ele. Contrariamente a esse comportamento perante o Mal, o filósofo adverte ser necessário reconhecer o direito que temos de discorrer sobre ele, esmiuçar suas estratégias, tomar consciência de sua proximidade:

É preciso despertar o princípio do Mal vivo no maniqueísmo e em todas as grandes mitologias para afirmar, contra o princípio do Bem, não exatamente a supremacia do Mal, mas a duplicidade fundamental que exige que uma ordem, qualquer que seja, só exista para ser desobedecida, atacada, ultrapassada, desmantelada (BAUDRILLARD, 1996, p. 68).

O pensador esclarece que os povos ancestrais agiam de modo análogo com o propósito de tirar do Mal as energias necessárias para a renovação da vida. Não reconciliavam o Bem e o Mal, mas confrontavam este como estratégia fatal de retirar dele todo o poder possível e, assim, o enfraquecer. Nos tempos atuais, a estratégia, segundo Baudrillard, seria negar a irrealidade do mundo e entender que o objeto é translúcido ao princípio do Mal, porque se constitui na duplicidade profunda do sujeito, da ordem social e política. Nisto se encontra a ironia do sujeito: sua obediência banal reside em que ela contém o segredo da desobediência 
fatal, "rapto, violação, receptação e malversação irônica da ordem simbólica" (BAUDRILLARD, 1996, p. 161).

Sophia escolhe quase sempre não mostrar o Mal em sua obra e reconhece que alguns artistas o empregam como objeto de suas criações, como António Osório (PRADO COELHO, 1986, p. 9). Na entrevista a Prado Coelho e a Miguel Serras Pereira, no entanto, ela cita o conto "A viagem", cujo tema perpassa o Mal, embora seu direcionamento aludisse à busca de maneiras de se libertar, por meio dele fazer a catarse, ocasião em que fala sobre o modo como enfrenta o Mal em sua obra:

Há uma noção de abismo que é imanente a toda experiência humana. A Terra é uma bola suspensa no espaço segundo um equilíbrio que não dominamos. E eu sei que há abismo também na poesia. Mas esta funciona muitas vezes como esconjuro do mal e da sombra e tem uma dimensão catártica que talvez seja o que faz com que o medo não me assalte do mesmo modo. Com a prosa, surge uma dúvida dentro de nós. Não sabemos nunca se estamos a esconjurar, se a convocar. É uma espécie de jogo muito estranho (ANDRESEN apud PEREIRA, 1985, p. 3).

Sua ideia sobre lidar com o Mal não apenas na poesia, mas também na vida social, vem acompanhada da declaração de que o Mal lhe dá medo: "Tenho medo de tudo. Só não tenho medo da polícia. Só não tenho medo da política. De resto, tenho medo de tudo. Tudo é para ter medo! Vivemos rente à deriva e a destruição corre atrás de nós..." (ANDRESEN apud PASSOS, 1982, p. 4). O diálogo de Sophia com os entrevistadores sobre o Mal e o medo em sua obra levam a entender que ela escolhe aspectos relativos a esses temas de modo a evitar ser tragada por inquietações que ela situa no "abismo", talvez porque a poetisa tenha vivenciado em Portugal por muito tempo uma das formas do Mal, a ditadura.

Se Sophia prefere não suscitar com frequência temas concernentes ao Mal em sua obra, ela diz, nas entrevistas, que em seus textos de prosa e poesia há ressonâncias do caos, que ela define como "um pouco aquele mundo de coisas múltiplas, diversas, contraditórias, assustadoras que enfrentamos na infância e que não conseguimos organizar dentro de nós, decifrar, compreender, mas que ao mesmo tempo são muito ricas" (PASSOS, 1982, p. 4). Retomamos a afirmação de Sophia, "do Mal não nasce nada", para deduzir que, em vez de seu tratamento poético contribuir 
com o acordo entre os membros de um grupo social, pode, pelo contrário, destruir essa organização. Assim, a poetisa deixa implícita a ideia de que, se o homem escolhe o Mal, ele se afasta da consciência moral. Por outro lado, a partir do caos o homem apreende e recria o mundo, e isso se dá tanto pela linguagem usada para firmar o acordo sobre as coisas do mundo nos sistemas sociais, quanto pela linguagem empregada para questionar o mesmo acordo e transgredir leis que favorecem um grupo em detrimento de outros nos citados sistemas. Assim, o caos possui dinâmica criadora e recriadora aos olhos de Sophia, e de modo semelhante àquele em que ela cria o poema a partir das palavras que ela retira do caos, ela ressalta a urgência de transformar a vida caótica nos centros urbanos em vida participada entre os cidadãos, sob o risco de o homem deixar abertura para o Mal que ameaça destruí-lo.

A discussão sobre a participação política, feita por Sophia, decorre de um conjunto de ideias baseadas na possibilidade de o homem viver em uma cidade hipodâmica, utópica, planejada para favorecer a ótima qualidade de vida dos cidadãos, próxima das cidades que "os gregos primeiro construíram, a cidade que nasce, não do acaso, mas do arquiteto [sendo] por isso uma cidade [...] proporcionada e ordenada", embora as cidades que nascem do acaso "tenham outro apelo e haja nelas outro tipo de aventura" (ANDRESEN apud PRADO COELHO, 1986, p. 6). Essa ideia de Sophia articula, portanto, a regra de bem viver na pólis grega com a responsabilidade social, transmitida por seus pais, pensamento que, segundo a poetisa, a levou a não ser conivente com a injustiça, com o sofrimento do outro (ANDRESEN apud PRADO COELHO, 1986, p. 6).

Os dois temas se relacionam com a necessidade de o homem viver segundo a ética, conforme a poetisa fala na entrevista "Sophia: 'Sou uma mistura de Norte e Sul'", a evidenciar que cultura não é apenas atividade cultural, mas também o cuidado com o lugar onde se vive, o emprego da língua materna nos diferentes e variados espaços de comunicação, tendo em vista que a língua não apenas se constitui no elemento de preservação da cultura como também contém o germe de transformação de comportamentos que impedem a boa convivência social. Segundo Sophia, um dos fatores para o homem se religar à vida social é não compactuar "com a pobreza, a miséria, a solidão, o abandono, o sofrimento, a agonia".

Os temas destacados nas entrevistas vinculam-se aos acontecimentos e às demandas históricas de Portugal e do restante do 
mundo na época de Sophia de Mello Breyner Andresen: o entre-guerras, quando ela nasce; o pós-guerras, com a Guerra Fria e o surgimento das ditaduras na Europa e nas Américas, que desenvolvem as formas de violência exercidas sobre determinados grupos sociais que passam a ser condenados à marginalidade e/ou ao extermínio, como também os crimes contra prisioneiros e adversários políticos - como em Kosovo, em 1978. Estes últimos fatos mencionados ocorreram quando a poetisa era uma das vozes intelectuais de Portugal.

Apesar do contexto dramático que marca o século XX e por causa disso também, os temas, nas entrevistas, muitas vezes são tratados com humor mordaz por meio do qual a poetisa concentra a crítica aos problemas que impedem a boa qualidade de vida social em Portugal, como quando Sophia se refere à informação distorcida que alguns portugueses têm da história do país:

Claro que há, por outro lado, o problema da história e a esse respeito penso que certos portugueses, do mesmo modo que comem as sílabas, têm complexos em relação ao passado. Pensam que o caminho marítimo para a Índia foi descoberto por Salazar e que a primeira viagem ao Brasil foi feita por Tomás. Imaginam que os Descobrimentos foram uma invenção do Estado Novo (ANDRESEN, 1985, p. 3).

A crítica mordaz abrange uma parte da história de Portugal que propiciou, segundo a entrevistada, desde uma espécie de descuido no emprego da língua materna até à possível desinformação que poderia ser resolvida se o sistema educacional do país tivesse eficácia quanto à quantidade de pessoas que neste sistema pudessem ingressar e à qualidade de seu alcance. O humor ácido de Sophia de Mello Breyner Andresen precisa ser entendido dentro daquele momento em que ela concede a entrevista, na década de oitenta, dez anos após a Revolução dos Cravos, quando certamente os intelectuais portugueses esperavam que já houvesse tempo razoável para que as ideias incutidas na maioria dos portugueses, por parte da longa ditadura, tivessem mudado e que as instituições administrativas e políticas estivessem contribuindo para este propósito. Como se sabe da história da humanidade, no entanto, há um conjunto de fatores que operam as transformações, dentre eles o que a própria Sophia chama de prestar atenção ao real para decidir sobre como conquistar um modo de vida com boa qualidade. 
Assumindo discurso aproximado ao de Sophia de Mello Breyner Andresen, o pensador Edgar Morin, em Amor, poesia, sabedoria, afirma que no século XX predomina a hiperprosa, em decorrência do excesso de fragmentação, do risco de destruição e do automatismo a que o homem está submetido. Contra essa situação, Morin propõe que se crie a hiperpoesia, pela qual o homem pode encontrar mecanismos para a salvação terrestre que implica

aperfeiçoar as relações humanas e civilizar a humanidade. [...] Acredito que agora seja necessário dizer: sejamos irmãos porque estamos perdidos num planeta suburbano, de um sol suburbano, de uma galáxia periférica, de um mundo desprovido de centro. Mesmo assim, possuímos plantas, pássaros, flores, assim como a diversidade de vida, as possibilidades do espírito humano. Doravante, aqui residirão nosso único fundamento e nosso único recurso possível (MORIN, 1998, p. 40-41).

Segundo ele, as descobertas recentes do lugar da Terra no universo e das vidas microscópicas favorecem, agora, o diálogo entre a ciência e a poesia, de modo que a astrofísica tenha poesia, que a microbiologia tenha poesia. Morin liga ao contexto da busca da salvação terrestre e da reaproximação da ciência no século XX com a poesia a "consciência dos limites", ainda restrita a alguns setores da vida, e a "consciência da falta" (MORIN, 1998, p. 49), esta decorrente da situação de fragmentação em que grande parte dos homens no mundo ocidental se encontra e do excesso de racionalização, que tem afastado a poesia da prosa da vida. Esses fatores impossibilitam que, no século XX, se viva plenamente com base na sabedoria.

No entanto, nesse tempo, a sabedoria está implícita ou se apresenta como perspectiva "no esforço da autoética", exemplificada em Mandela, a qual, segundo Morin, se mostra nas seguintes ações: "evitar a baixeza, evitar ceder às pulsões vingativas e maldosas. Isto supõe muita autocrítica, autoexame, aceitação da crítica do outro. [...] A autoética é, antes de mais nada, uma ética da compreensão" (MORIN, 1998, p. 61). $\mathrm{O}$ autor associa este centro da sabedoria na vida do século XX com a vida antiga no Oriente quanto ao fato de eles saberem se distanciar de si mesmos para se objetivarem e se olharem como o outro sem perderem a consciência de que são sujeitos. Ele sugere que é possível aprender a autoética por meio da atitude reflexiva que seja um ensaio a respeito de 
várias informações e impressões fornecidas de um objeto para iniciar sua compreensão sem que esta seja definitiva, de tal modo que permita a abertura para aceitar outros elementos, mesmo que sejam antagônicos aos dados adquiridos anteriormente. Morin reconhece que as outras linhas de ação em que a sabedoria pode ser encontrada pressupõem o diálogo entre sapiens e demens e entre a prosa e a poesia.

As ideias de Morin convergem para alguns temas levantados nas entrevistas de Sophia de Mello Breyner Andresen, os quais se descrevem a seguir: Primeiro, a poetisa cita alguns escritores que constroem suas obras com a consciência de que a palavra poética se configura como um diálogo tenso entre a prosa da vida e a poesia da vida. Na entrevista "Escrevemos para não nos afogarmos no caos", a poetisa primeiramente afirma que concorda com a ideia de Mallarmé de que "o poeta vem transformar o caos em cosmos" e depois cita o verso "encontrar um puro domínio humano entre o rio e a rocha", que ela atribui a Rilke, para dizer que sua poesia oscila entre a confiança na unidade da vida social e o "pânico do seu fracasso" (ANDRESEN, 1986, p. 2 e 5).

A salvação terrestre, para Sophia, envolve questões da ecologia referente à responsabilidade dos habitantes de uma cidade. No primeiro caso, na entrevista a Eduardo Prado Coelho, Sophia diz que, na altura dos anos 80 , ela acredita que a política partidária talvez não seja tão mais importante que as modificações culturais. De acordo com Sophia, "Era preciso que a cultura viesse para o espaço da vida quotidiana e que isso fosse partilhado por toda a gente. Por exemplo, na luta pelo ambiente, pela defesa da natureza, pela qualidade de vida. Na luta contra as centrais elétricas" (ANDRESEN, 1986, p. 13). Assim, a salvação se dá na vida cotidiana, no posicionamento que o homem assume diante das exigências sociais que a ele se impõem.

O tema da autoética apresenta-se nas entrevistas quando a poetisa esclarece sua postura política, quando trata do processo poético da despersonalização, bem como da descolonização dos países da África. $\mathrm{Na}$ primeira questão, ela diz: "fundamentalmente o que está na base da minha opção política é o não aceitar o escândalo. É o não aceitar que haja pessoas inteiramente sacrificadas. $\mathrm{O}$ considerar que não é possível passar por cima do cadáver dos outros ou por vidas diminuídas e desumanizadas" (ANDRESEN, 1986, p. 3). Na segunda questão, a despersonalização - que se constitui em uma das grandes marcas da poesia sophiana - constitui-se no fato de que "a arte é uma mimesis 
que só se dá quando o artista põe o eu entre parênteses [...] a pessoa que escreve procura [...] tornar-se uma página em branco, criar em si própria um certo vazio". Assim, o artista olha e fala sobre as coisas e das alegrias e dores dos outros. A poetisa acrescenta que em seus poemas escreve para ser entendida por todos. (ANDRESEN, 1986, p. 9-10). Na terceira questão, Sophia observa que uma das consequências positivas do 25 de abril de 1974 foi a descolonização, porque, segundo ela, "a aventura extraordinária dos Descobrimentos cumpre-se na independência dos povos. Criaram-se nações novas e livres, cheias de possibilidades" (ANDRESEN, 1989, p. 101).

Contrariamente aos desencontros que o homem gera e sofre, Sophia fala da urgência de redescobrir a imanência, de o homem voltar a se sentir parte do cosmo. Seu pensamento está inter-relacionado com o dos filósofos de seu tempo, Félix Guattari, Leonardo Boff e David Harvey, entre outros. Guattari, em As três ecologias, discorre sobre a urgência de o homem voltar a entrar em sinergia com a natureza, consigo e com a coletividade por meio da articulação ético-política. Isso demandará o redimensionamento das relações interpessoais, do homem com a natureza - que não pode mais ser tratada como propriedade do homem para a extração de riquezas do solo, da floresta, da água, para a produção e o consumo de bens materiais - e com o revigoramento das riquezas imateriais - os saberes de povos ancestrais aliados ao conhecimento científico. O filósofo observa que estão ocorrendo transformações de alguns comportamentos prejudiciais ao convívio social a partir de movimentos reivindicatórios de grupos que até agora têm sido marginalizados pelo sistema capitalista, burguês e patriarcal, como os grupos das feministas, dos negros, das etnias indígenas. Leonardo Boff possui ideia aproximada à de Sophia de Mello Breyner Andresen e de Félix Guattari em sua proposta de ecoespiritualidade, designada como experiência radical, para além das doutrinas religiosas institucionalizadas, mas das quais muitos princípios poderão ser combinados, e por meio da qual o homem se sentirá como parte da Terra, não podendo dela se separar sob pena de provocar não apenas a destruição de seu habitat, mas a destruição dele próprio. David Harvey discorre sobre a possibilidade de o homem aproveitar-se dos pontos frágeis do capitalismo para criar alternativas de transformação social radicais, os espaços da esperança. São propostas que buscam caminhos outros para evitar a autodestruição para a qual o homem tem se dirigido. Corroborando com essa linha de pensamento redimensionador do modo de viver do homem, Sophia de 
Mello Breyner Andresen reflete sobre transformar a vida caótica antes que a abertura que ele deixa para o mal o destrua.

\section{Consideração finais}

As críticas de Sophia de Mello Breyner Andresen, na altura dos anos 80 e 90, devem ser entendidas como decorrentes das expectativas que haviam sido projetadas no âmbito social após o 25 de abril, muitas das quais não puderam ser executadas. Observa-se que a poetisa atribuía o insucesso das políticas sociais a questões administrativas, como também ao fato de grande parcela dos portugueses não demonstrarem responsabilidade com a cidade que habitavam, com a língua materna e com a história do país. Sophia relacionava tais problemas ao mal e os colocava em evidência, nas entrevistas, às vezes com mordacidade, para que eles fossem eliminados. E o modo de o fazer seria por meio da atenção à vida, da valorização de todas as atividades cotidianas.

Em torno dessas questões residia a preocupação de Sophia com a criação e implementação de projetos socioeconômicos que favorecessem o redimensionamento tanto das instituições governamentais quanto da mentalidade do homem português, projeto a ser construído por um corpo social que ainda estava tomando consciência da necessidade de seus papéis no território nacional e no restante do mundo.

A vida pública de Sophia de Mello Breyner Andresen, que se mostra por seus posicionamentos nas entrevistas aqui mencionadas, como também na sua escrita poética, é norteada pela ética. Pode-se mesmo afirmar que esse é o núcleo no qual as demais temáticas se conjugam, conforme se verifica desde o livro Poesia até O búzio de Cós e outros poemas. Certamente o fato de a poetisa ter vivido num século marcado por duas grandes guerras, guerras civis, ditaduras na Europa e na América, descolonização da África, geração hippie, movimentos feministas e de outras demandas de libertações políticas, é fundamental para sua obra - tendo sido iniciada na década de 40 e tendo se desenvolvido até o final dos anos 90, com poesia, ficção, tradução, ensaios, peças de teatro e intervenções - que se constrói neste cenário dos conflitos que predominaram no século XX. 


\section{Referências}

ANDRESEN, Sophia de Mello Breyner. Escrevemos poesia para não nos afogarmos no cais. Jornal de Letras, Artes e Ideias, Lisboa, 16 fev. 1982. Entrevista concedida a Maria Armanda Passos.

ANDRESEN, Sophia de Mello Breyner. Sophia: Sou uma mistura de Norte e Sul". Jornal de Letras Artes e Ideias, Lisboa, n. 135, 05 fev. 1985. 2-3. Entrevista concedida a Miguel Serras Pereira.

ANDRESEN, Sophia de Mello Breyner. Uma personalidade - um tempo - uma obra. ICALP Revista, Lisboa, n. 6, ago./dez. 1986. Entrevista concedida a Eduardo Prado Coelho. Disponível em: $<$ www.institutocamoes.pt/escritores/sophia/sophiaepc.htm>. Acesso em: 18 mar. 2004.

ANDRESEN, Sophia de Mello Breyner. Luzes de Sophia. Revista Vida Mundial, Lisboa, Série IV, n. 2, p. 96-103, 31/05 a 06/06/1989. Entrevista concedida a Lúcia Sigalho e Sandra Martins.

ANDRESEN, Sophia de Mello Breyner. Sophia: a luz dos versos. Jornal de Letras, Artes e Ideias, Lisboa, 25 jun. 1991. Entrevista concedida a José Carlos Vasconcelos.

ANDRESEN, Sophia de Mello Breyner. Geografia. 5 ed. Porto: Assírio \& Alvim, 2014.

BAUDRILLARD, Jean. As estratégias fatais. Tradução de Ana Maria Scherer. Rio de Janeiro: Rocco, 1996.

BIBLIOTECA NACIONAL DE PORTUGAL. “Sophia”. Disponível em: $<$ http://www.bnportugal.pt/index.php?option=com_content\&view=art icle\&id=572: espolio-sophia-bnp\&catid $=144: 2010 \&$ lang $=p t>$. Acesso: 12 jul. 2018.

MEDINA, Maria Cremilda. Entrevista: o diálogo possível. 4. ed. São Paulo: Ática, 2004.

MOISÉS, Massaud. A criação literária: prosa II prosa poética, ensaio, crônica, teatro, jornalismo e crítica literária. 15. ed. São Paulo: Cultrix, 1997.

MORÃO, Paula; AMADO, Teresa (Org.). Catálogo da Exposição "Sophia de Mello Breyner Andresen - uma vida de poeta". Biblioteca 
Nacional de Portugal. 26/01/2011 a 30/04/2011. Lisboa: Editora Caminho, 2010.

MORIN, Edgar. Amor, poesia, sabedoria. Rio de Janeiro: Bertrand Brasil, 1998.

TAVARES, Maria Andresen de Sousa (Coord.). O espólio de Sophia na BNP, [s.d.] Disponível em: <http://purl.pt/19841/1/bibliografia/ bibliografia-sitio.html $>$. Acesso em: 12 jul. 2018.

TAVARES, Maria Andresen; CENTRO NACIONAL DE CULTURA (Org.). Sophia de Mello Breyner Andresen: Actas do Colóquio Internacional. Porto: Porto Editora, 2013. 